OPEN ACCESS

Edited by: Sergi Sabater,

University of Girona, Spain

Reviewed by:

lleana Espejel,

Autonomous University of Baja

California, Mexico

Nidhi Nagabhatla,

United Nations University Institute for

Water Environment and Health,

Canada

*Correspondence:

R. T. Kingsford

richard.kingsford@unsw.edu.au

Specialty section:

This article was submitted to

Freshwater Science,

a section of the journal

Frontiers in Environmental Science

Received: 18 December 2020

Accepted: 08 February 2021

Published: 22 March 2021

Citation:

Kingsford RT, Bino G, Finlayson CM,

Falster D, Fitzsimons JA, Gawlik DE,

Murray NJ, Grillas $P$, Gardner RC,

Regan TJ, Roux DJ and Thomas RF

(2021) Ramsar Wetlands of International Importance-Improving

Conservation Outcomes.

Front. Environ. Sci. 9:643367.

doi: 10.3389/fenvs.2021.643367

\section{Ramsar Wetlands of International Importance-Improving Conservation Outcomes}

\author{
R. T. Kingsford ${ }^{1 *}$, G. Bino ${ }^{1}$, C. M. Finlayson ${ }^{1,2}$, D. Falster ${ }^{3}$, J.A. Fitzsimons ${ }^{4,5}$, D. E. Gawlik ${ }^{6}$, \\ N. J. Murray ${ }^{7}$, P. Grillas ${ }^{8}$, R. C. Gardner ${ }^{9,10}$, T. J. Regan ${ }^{11,12}$, D. J. Roux ${ }^{13,14}$ and \\ R. F. Thomas ${ }^{1,15}$
}

${ }^{1}$ Centre for Ecosystem Science, School of Biological, Earth and Environmental Sciences, UNSW Sydney, Sydney, NSW, Australia, ${ }^{2}$ HHE Delft Institute for Water, Institute for Water Education, Delft, Netherlands, ${ }^{3}$ Evolution and Ecology Research Centre, School of Biological, Earth and Environmental Sciences, UNSW Sydney, Sydney, NSW, Australia, ${ }^{4}$ The Nature Conservancy, Carlton VIC, Australia, ${ }^{5}$ School of Life and Environmental Sciences, Deakin University, Burwood, VIC, Australia, ${ }^{6}$ Harte Research Institute, Texas A\&M University Corpus Christi, Corpus Christi, TX, United States, ${ }^{7}$ College of Science and Engineering, James Cook University, Townsville, QLD, Australia, ${ }^{8}$ Tour du Valat, Institute for the conservation of Mediterranean wetlands, Arles, France, ${ }^{9}$ Institute for Biodiversity Law and Policy, Stetson University College of Law, Gulfport, FL, United States, ${ }^{10}$ Institute for Land, Water \& Society, Charles Sturt University, Albury, NSW, Australia, ${ }^{11}$ Arthur Rylah Institute for Environmental Research, Department of Environmental, Land, Water and Planning, Heidelberg, VIC, Australia, ${ }^{12}$ School of Biosciences, The University of Melbourne, Parkville, VIC, Australia, ${ }^{13}$ Scientific Services, South African National Parks, George, South Africa, ${ }^{14}$ Sustainability Research Unit, Nelson Mandela University, George, South Africa, ${ }^{15}$ Environment, Energy, and Science, NSW Department of Planning, Industry and Environment, Lidcombe, NSW, Australia

The Ramsar Convention (or the Convention on Wetlands), signed in 1971, was one of the first international conservation agreements, promoting global wise use of wetlands. It has three primary objectives: national designation and management of wetlands of international importance; general wise use of wetlands; and international cooperation. We examined lessons learnt for improving wetland conservation after Ramsar's nearly five decades of operation. The number of wetlands in the Ramsar Site Network has grown over time $(2,391$ Ramsar Sites, 2.5 million $\mathrm{km}^{2}$, as at 2020-06-09) but unevenly around the world, with decreasing rate of growth in recent decades. Ramsar Sites are concentrated in countries with a high Gross Domestic Product and human pressure (e.g., western Europe) but, in contrast, Ramsar Sites with the largest wetland extent are in central-west Africa and South America. We identified three key challenges for improving effectiveness of the Ramsar Site Network: increasing number of sites and wetland area, improved representation (functional, geographical and biological); and effective management and reporting. Increasing the number of sites and area in the Ramsar network could benefit from targets, implemented at national scales. Knowledge of representativeness is inadequate, requiring analyses of functional ecotypes, geographical and biological representativeness. Finally, most countries have inadequate management planning and reporting on the ecological character of their Ramsar Sites, requiring more focused attention on a vision and objectives, with regular reporting of key indicators to guide management. There are increasing opportunities to rigorously track ecological character, utilizing new tools and available indicators (e.g., remote sensing). It is critical that the world protect its wetlands, with an effective Ramsar Convention or the Convention on Wetlands at the core.

Keywords: Ramsar Convention, International agreement, ecological character, river conservation, risk assessment 


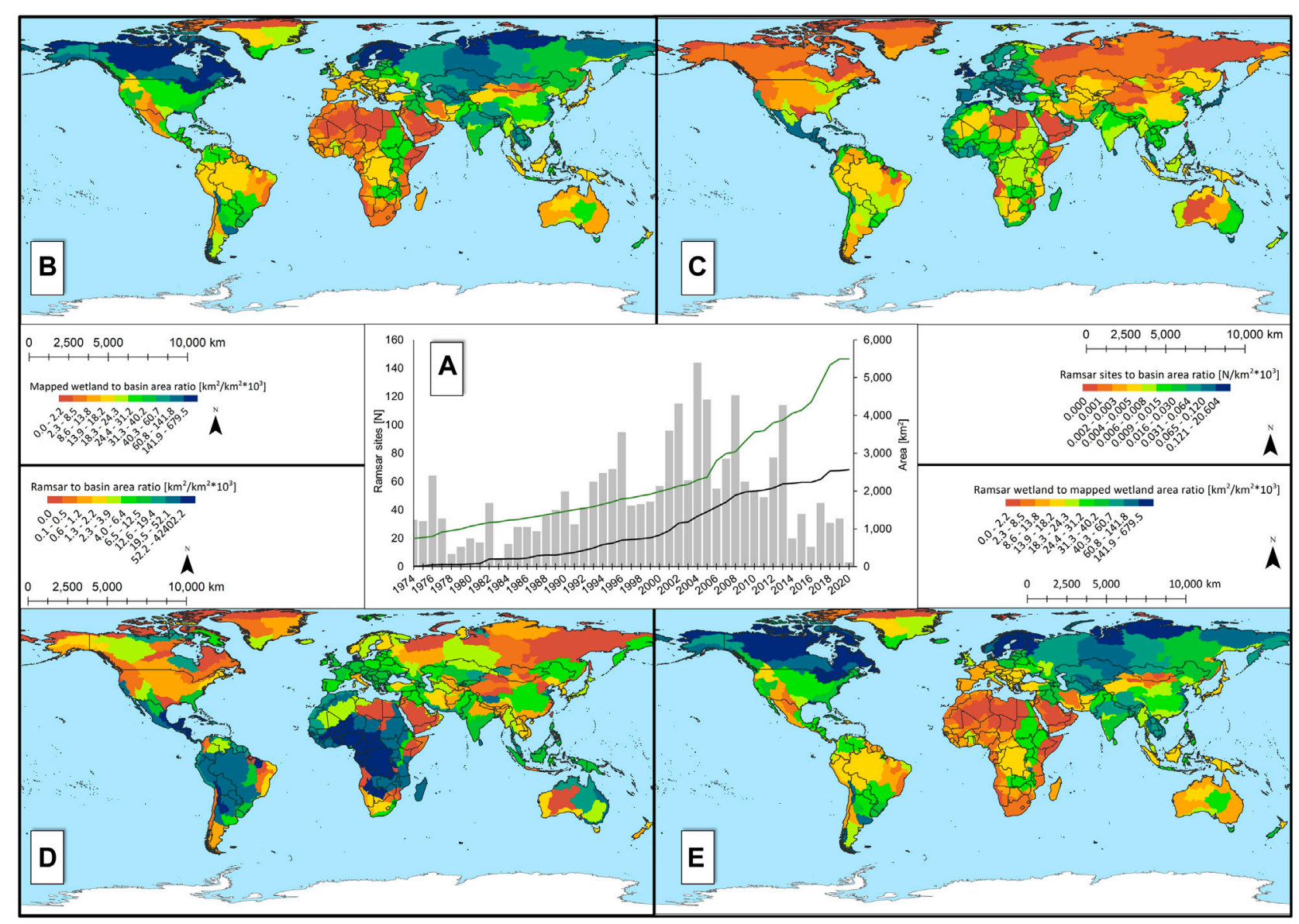

FIGURE 1 | (A) Cumulative wetland area in the Ramsar Site Network (black line, $\mathrm{km}^{2} \times 10^{3}$ ) and terrestrial protected areas (green line, $\mathrm{km}^{2} \times 10^{4}$ ), with annual new numbers of Ramsar Sites (gray histograms), 1974-2020, with maps showing national borders (https://datacatalog.worldbank.org/dataset/world-bank-officialboundaries) and relative estimates of number or area of Ramsar Sites within river basins (Level 3 (Lehner and Grill, 2013)), including (B) ratio of mapped wetland area to basin area $\left(\mathrm{km}^{2} / \mathrm{km}^{2} \times 10^{3}, 1984-2018\right.$, (Pekel et al., 2016), Source: EC JRC/Google); (C) number of Ramsar Sites relative to basin area ratio (N/km² $\left.\times 110^{3}\right) ;($ (D) ratio of Ramsar Site area to basin area $\left(\mathrm{km}^{2} / \mathrm{km}^{2} \times 10^{3}\right)$ and; $(\mathbf{E})$ ratio of Ramsar Site area to mapped wetland area $\left(\mathrm{km}^{2} / \mathrm{km}^{2} \times 10^{3}\right)$. Data also provided for each country (Supplementary Table S1).

\section{INTRODUCTION}

Water crises and the collapse of biodiversity and ecosystems are among the top global risks to human well-being (World Economic Forum, 2019). Globally, wetlands have declined by $35 \%$ from 1970 to 2015, where data are available (Darrah et al., 2019). Such loss and degradation of wetlands and their ecosystem services is increasingly expressed in global initiatives (e.g., Convention on Biological Diversity Aichi targets, Sustainable Development Goals 6 and 15 and associated targets). The Ramsar Convention (the Convention on Wetlands), signed in 1971 and legally effected in 1975, was one of the first modern multilateral environmental agreements advancing protection of wetlands through international collaboration and effective management.

The Convention includes palustrine, riverine, estuarine, lacustrine wetlands and near shore systems, including reefs. Over nearly five decades, 171 (as at 2020-06-09) contracting parties (i.e., countries) have prioritized the conservation and wise use of wetlands, and by listing wetlands assessed as internationally important and committing to maintaining their ecological character (Gardner and Davidson, 2011; Davidson et al., 2019). However, ecological character, the combination of ecosystem components, processes and benefits (Davidson et al., 2019), is increasingly deteriorating in Ramsar Sites (Davidson et al., 2020). These can be tracked by measuring key ecological indicators, including threats, which cause degradation (Davis and Brock 2008).

The Ramsar Strategic Plan 2016-2024 has three strategic goals, to: 1) address the drivers of wetland loss and degradation; 2) effectively conserve and manage the Ramsar Site Network; and 3) wisely use all wetlands (Ramsar Convention Secretariat, 2016). Targets include increasing the area, numbers, and ecological connectivity of Ramsar Sites, focusing on under-represented regions or types, and effective management. We provide a perspective on achieving these goals and targets, focusing on two key objectives: 1) identification of biases in the current global distribution of the Ramsar Site Network and 2) a conceptual 
adaptive management framework, linking maintenance of ecosystem dynamics with drivers of change.

\section{RAMSAR SITE NETWORK}

The number of Ramsar Sites $(2,391)$ and their area (2.54 million $\mathrm{km}^{2}$ as at June 2020) have increased, but the rate of increase in area has slowed, contrasting a steady growth in protected area (Figure 1A), reflected in various regional analyses (Mauerhofer et al., 2015; Fritz et al., 2017). Given that effective management of most inland wetlands is dependent on flow and flooding regimes of rivers (Saunders et al., 2002; Kingsford et al., 2016), we examined the distribution of Ramsar Sites and their areas, at the river basin scale (Lehner and Grill, 2013), relative to maximum extent of inland surface water between 1984 and 2018 (https://www.ngdc.noaa.gov/mgg/shorelines/gshhs.html; Pekel et al., 2016, Source: EC JRC/Google). Such mapping generally excluded vegetative flooded areas, while Ramsar Site areas included terrestrial ecosystems.

The world's mapped wetlands are predominantly in the Northern Hemisphere (Figure 1B; Supplementary Table S1), different to the distribution of numbers of Ramsar Sites (Figure 1C) with relatively higher numbers of Ramsar Sites in Europe, parts of South America, Central America, Northern, Central and Western Africa, Southern Asia and eastern Australia (Supplementary Table S1), reflecting Northern Hemisphere bias (Rebelo et al., 2009). Growth in numbers of Ramsar Sites has continued linearly in Europe since the beginning of the Convention on Wetlands, contrasting most other regions of the world where significant growth only began after about 2000 (Supplementary Figure S1). In contrast, Ramsar Site area, relative to basin area, is higher in the Southern Hemisphere (Figure 1D; Supplementary Table S1) and at a higher density relative to mapped wetland area (Figure 1E; Supplementary Table S1). Much of this growth in Ramsar Site area has occurred in Africa and Latin America (Supplementary Figure S1). Numbers and area of Ramsar Sites has continued to grow in Europe, Africa, Asia and Latin America but plateaued in North America and Oceania (Supplementary Figure S1).

We also explored possible associations among countries between the number and area of Ramsar Sites, area of mapped inland surface water (Pekel et al., 2016), area of protected areas (UNEP-WCMC and IUCN, 2020), Gross Domestic Product (GDP) (GIS processing World Bank DECRG, 2010) and Human Footprint Index (HFP, sum and mean, (Venter et al., 2018); Supplementary Figure S2). The number of Ramsar Sites was also positively related to HFP and surface water area (Pekel et al., 2016), slightly correlated to protected area and not to GDP (Supplementary Figure S2). This could reflect the high number of Ramsar Sites in the Northern Hemisphere, with relatively high HFP, contrasting to Ramsar Site area potentially associated with countries with lower GDP and HFP.

\section{Adaptive Management Framework}

Effective management and reporting is a significant challenge, given many Ramsar Sites lack management plans, and there is inadequate reporting of ecological character trajectories (Davidson et al., 2019; Davidson et al., 2020). Social-ecological interconnectedness and feedbacks are essential for hydrologically connected freshwater ecosystems, requiring collaboration of managers, scientists and stakeholders (Lee, 1999; Huitema et al., 2009; Novellie et al., 2016). Conceptually, adaptive management of a Ramsar Site needs a vision of a desired future state, involving stakeholders, clear objectives, triggers, risk assessment supported by co-design and co-management actions, and transdisciplinary science, with evaluation, reporting and updating (Kingsford et al., 2011; Westgate et al., 2013; Davidson et al., 2019; Davidson et al., 2020; Figure 2A).

Direct and indirect biotic and abiotic (natural and anthropogenic) drivers affecting ecosystem processes, characteristic biota and ecosystem services need to be incorporated (Figure 2B). In socialecological systems such as Ramsar Sites, there should also be a focus on how demographic, economic, sociopolitical and cultural factors link to natural biotic and abiotic drivers, incorporated into management (Figure 2B; Carpenter et al., 2006). Scientific analysis can then track change, diagnosing causes, and informing management, informed by understanding of the interactions of these drivers on changes to ecological character (Figure 2C). Ecosystem dynamics need to be conceptually simplified, characterizing requisite simplicity of an ecosystem (Holling, 2001; Stirzaker et al., 2010). Simple conceptual models can be used to identify primary drivers (Keith et al., 2020), which usually include flow (surface and ground water) and/or flooding regimes, nutrients and water quality. Such models guide choice of indicators, with data available locally (e.g., waterbirds, fish), regionally (e.g., rainfall, river flows) or globally (e.g., remote sensed inundation and land cover) (Figure 2C). Indicator data can be used to report on the condition of the wetland or ecological character over time, guiding management. For example, loss of a key bird species, a measure of ecological character, in a Ramsar wetland in Chile was was legally judged to have been caused by paper mill discharge impacting an aquatic plant, the bird's main food supply (Marín et al., 2018).

\section{DISCUSSION}

After nearly five decades, the listing of 2,391 Ramsar sites is an impressive contribution to global biodiversity conservation (Figure 1A). Over the same period, our population has more than doubled, increasingly threatening fresh water for wetlands, diverted for drinking, irrigation and energy. Many ecosystem services provided by wetlands are in decline (Gardner and Finlayson, 2018; Darrah et al., 2019; McInnes et al., 2020). A declining rate of growth in Ramsar Site area in some regions (Figure 1A; Supplementary Figure S1) may reflect this inability to maintain ecological character, highly dependent on flow and flooding regimes (Kingsford et al., 2016), potentially hampering achievement of Aichi Biodiversity Target 11 (Juffe-Bignoli et al., 2016).

More effective implementation of the Convention on Wetlands is urgent (Geijzendorffer et al., 2019), particularly given the relatively poor condition of the world's wetlands, compared to other realms (Gardner and Finlayson, 2018). This can be done by increasing the area and number of Ramsar Sites; 


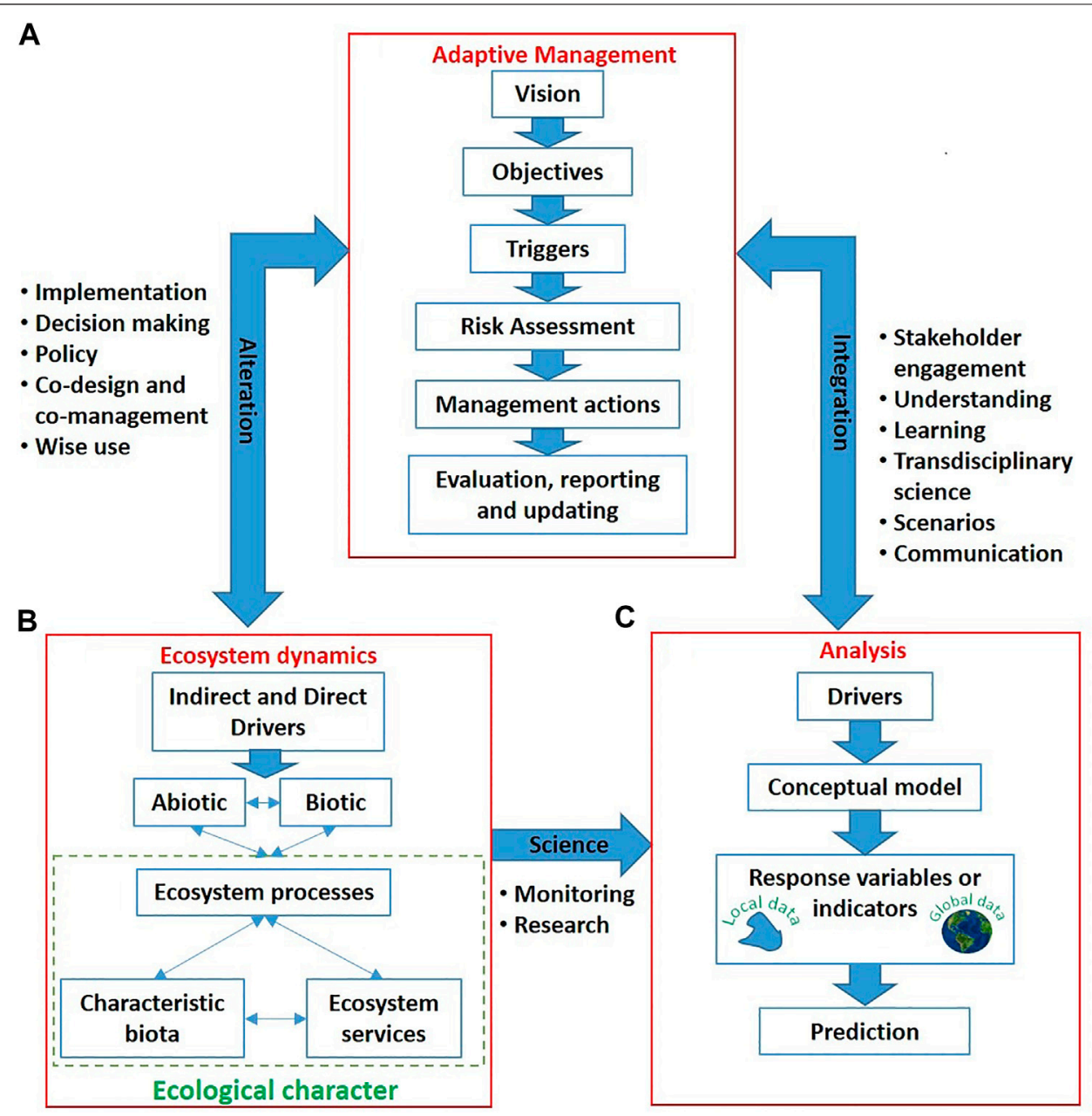

FIGURE 2 | Conceptual framework for three integrated processes aimed at tracking change for reporting and guiding and maintaining ecological character of Ramsar Sites: (A) adaptive management, (B) ecosystem dynamics (capturing ecological character) and (C) analysis of indicators (using local and global data).

improving representativeness (geographically, functionally, biologically); and implementing effective adaptive management. These issues areas are not new (e.g., Davidson et al., 2019; Davidson et al., 2020; Gaget et al., 2020), undermining the goals and targets of the Ramsar Strategic Plan (Ramsar Convention Secretariat, 2016).

Increases in the Ramsar Site Network could be achieved by adopting national representative targets. This could be informed by using typological classifications (e.g., new IUCN typology: Keith et al., 2020, https://global-ecosystems.org/) to improve representativeness (Figures 1B-E; recognising mapping shortcomings, such as those in Pekel et al., 2016). Although highly dependent on national will (Davidson et al., 2019), opportunities exist to integrate targets across different commitments (e.g., United Nations Sustainable Development Goals and Aichi targets and Convention on Biological Diversity targets).

To improve management, we recommend implementing adaptive management frameworks, with stakeholders, targeting measurable indicators responsive to drivers that guide management and track ecological character effectively
(Figure 2). This means incorporating social-ecological dynamics (Cilliers et al., 2013), with indicators representing ecological character (Figure 2), tracking ecosystem change (Keith et al., 2013; Bland et al., 2017). With globally available historical data (e.g., palaeoecological, remote sensing), past and future scenario analyses can guide management choices (Kopf et al., 2015).

The Convention on Wetlands provides nearly five decades of commitment to sustainable development and wise use of wetlands, but considerable challenges remain for the world's wetlands. There are significant opportunities to improve national and global wetland conservation by better incorporating representativeness and implementing adaptive management. This would improve effectiveness and streamline and improve transparent reporting, which guides management for conservation.

\section{DATA AVAILABILITY STATEMENT}

The raw data supporting the conclusions of this article will be made available by the authors, without undue reservation. 


\section{AUTHOR CONTRIBUTIONS}

RK conceived the idea and led the writing of the paper, supported initially by GB, including data analyses, and CMF, and by other authors, listed alphabetically.

\section{FUNDING}

The Australian Research Council Linkage Grant (LP180100159), identifying a standard for reporting on ecological character of Ramsar Sites, and the Australian Research Council Australian Discovery Early Career Award (DE190100101, NM) supported us.

\section{REFERENCES}

Bland, L. M., Regan, T. J., Dinh, M. N., Ferrari, R., Keith, D. A., Lester, R., et al. (2017). Using multiple lines of evidence to assess the risk of ecosystem collapse. Proc. R. Soc. B 284, 20170660. doi:10.1098/rspb.2017.0660

Carpenter, S. R., DeFries, R., Dietz, T., Mooney, H. A., Polasky, S., Reid, W. V., et al. (2006). Millennium ecosystem assessment: research needs. Science 314, 257-258. doi:10.1126/science.1131946

Cilliers, P., Biggs, H. C., Blignaut, S., Choles, A. G., Hofmeyr, J.-H. S., Jewitt, G. P. W., et al. (2013). Complexity, modeling, and natural resource management. Ecol. Soc. 18 (3), 1. doi:10.5751/ES-05382-180301

Darrah, S. E., Shennan-Farpón, Y., Loh, J., Davidson, N. C., Finlayson, C. M., Gardner, R. C., et al. (2019). Improvements to the Wetland Extent Trends (WET) index as a tool for monitoring natural and human-made wetlands. Ecol. Indic. 99, 294-298. doi:10.1016/j.ecolind.2018.12.032

Davidson, N. C., Dinesen, L., Fennessy, S., Finlayson, C. M., Grillas, P., Grobicki, A., et al. (2019). A review of the adequacy of reporting to the Ramsar Convention on change in the ecological character of wetlands. Mar. Freshw. Res. 71, 117-126. doi:10.1071/MF18328

Davidson, N. C., Dinesen, L., Fennessy, S., Finlayson, C. M., Grillas, P., Grobicki, A., et al. (2020). Trends in the ecological character of the world's wetlands. Mar. Freshw. Res. 71, 127-138. doi:10.1071/MF18329

Davis, J., and Brock, M. (2008). Detecting unacceptable change in the ecological character of Ramsar wetlands. Ecol. Manage. Restor. 9, 26-32. doi:10.1111/j. 1442-8903.2008.00384.x

Fritz, K., Cid, N., and Autrey, B. (2017). "Governance, legislation, and protection of intermittent rivers and ephemeral streams," in Intermittent rivers and ephemeral streams. Editors T. Datry, N. Bonada, and A. Boulton (London: Elsevier Science Publishing Co.), 477-507.

Gaget, E., Le Viol, I., Pavón-Jordán, D., Cazalis, V., Kerbiriou, C., Jiguet, F., et al. (2020). Assessing the effectiveness of the Ramsar Convention in preserving wintering waterbirds in the Mediterranean. Biol. Conserv. 243, 108485. doi:10. 1016/j.biocon.2020.108485

Gardner, R., and Davidson, N. (2011). "The Ramsar Convention," in Wetlands: integrating multidisciplinary concepts, Editor B. LePage. (Dordrecht: Springer), 189-203.

Gardner, R., and Finlayson, C. M. (2018). Global wetland outlook: state of the world's wetlands and their services to people. Gland, Switzerland: Ramsar Convention.

Geijzendorffer, I. R., Beltrame, C., Chazee, L., Gaget, E., Galewski, T., Guelmami, A., et al. (2019). A more effective Ramsar Convention for the conservation of Mediterranean wetlands. Front. Ecol. Evol. 7, 21. doi:10.3389/fevo.2019.00021

GIS processing World Bank DECRG (2010). Gross Domestic Product extrapolation UNEP/GRID-Geneva. Washington, DC: GIS processing World Bank DECRG. Available at: https://datacatalog.worldbank.org/dataset/gross-domesticproduct- 2010

Holling, C. S. (2001). Understanding the complexity of economic, ecological, and social systems. Ecosystems 4, 390-405. doi:10.1007/s10021-001-0101-5

\section{ACKNOWLEDGMENTS}

We thank the environment agencies (Australian, New South Wales, Queensland, South Australian, Victorian governments), South Australian Arid Lands Board, The Nature Conservancy and the Lake Eyre Basin Partnership for support. Our views do not necessarily reflect those of supporting governments and our other partners.

\section{SUPPLEMENTARY MATERIAL}

The Supplementary Material for this article can be found online at: https://www.frontiersin.org/articles/10.3389/fenvs.2021.643367/ full\#supplementary-material.

Huitema, D., Mostert, E., Egas, W., Moellenkamp, S., Pahl-Wostl, C., and Yalcin, R. (2009). Adaptive water governance: assessing the institutional prescriptions of adaptive (Co-) management from a governance perspective and defining a research agenda. Ecol. Soc. 14 (1), 26. doi:10.5751/ES-02827-140126

Juffe-Bignoli, T. M., Brooks, C., Butchart, S. H. M., Jenkins, R. B., Hoffmann, M., et al. (2016). Assessing the cost of global biodiversity and conservation knowledge. Plos One 11 (8). doi:10.1371/journal.pone.0160640

Keith, D. A., Ferrer-Paris, J. R., Nicholson, E., and Kingsford, R. T. (2020). IUCN Global Ecosystem Typology v2.0: descriptive profiles for biomes and ecosystem functional groups. Available at: https://portals.iucn.org/library/node/49250 (Accessed December 18, 2020).

Keith, D. A., Rodriguez, J. P., Rodriguez-Clark, K. M., Nicholson, E., Aapala, K., Alonso, A., et al. (2013). Scientific foundations for an IUCN Red List of Ecosystems. PLoS One 8, e62111. doi:10.1371/journal.pone.0062111

Kingsford, R. T., Basset, A., and Jackson, L. (2016). Wetlands: conservation's poor cousins. Aquat. Conserv. Mar. Freshw. Ecos. 26, 892-916. doi:10.1002/aqc.2709

Kingsford, R. T., Biggs, H. C., and Pollard, S. R. (2011). Strategic Adaptive Management in freshwater protected areas and their rivers. Biol. Conserv. 144, 1194-1203. doi:10.1016/j.biocon.2010.09.022

Kopf, R. K., Finlayson, C. M., Humphries, P., Sims, N. C., and Hladyz, S. (2015). Anthropocene baselines: assessing change and managing biodiversity in humandominated aquatic ecosystems. BioScience 65, 798-811. doi:10.1093/biosci/biv092

Lee, K. N. (1999). Appraising adaptive management. Conserv. Ecol. 3 (2), 3. doi:10. 5751/ES-00131-030203

Lehner, B., and Grill, G. (2013). Global river hydrography and network routing: baseline data and new approaches to study the world's large river systems. Hydrol. Proc. 27, 2171-2186. doi:10.1002/hyp.9740

Marín, V. H., Delgado, L. E., Tironi-Silva, A., and Finlayson, C. M. (2018). Exploring social-ecological complexities of wetlands of international importance (Ramsar sites): the Carlos Anwandter Sanctuary (Valdivia, Chile) as a case study. Wetlands 38, 1171-1182. doi:10.1007/s13157-017-0935-Z

Mauerhofer, V., Kim, R. E., and Stevens, C. (2015). When implementation works: a comparison of Ramsar Convention implementation in different continents. Environ. Sci. Pol. 51, 95-105. doi:10.1016/j.envsci.2015.03.016

McInnes, R. J., Davidson, N. C., Rostron, C. P., Simpson, M., and Finlayson, C. M. (2020). A citizen science state of the world's wetlands survey. Wetlands 40, 1577-1593. doi:10.1007/s13157-020-01267-8

Novellie, P., Biggs, H., and Roux, D. (2016). National laws and policies can enable or confound adaptive governance: examples from South African national parks. Environ. Sci. Pol. 66, 40-46. doi:10.1016/j.envsci.2016.08.005

Pekel, J. F., Cottam, A., Gorelick, N., and Belward, A. S. (2016). High-resolution mapping of global surface water and its long-term changes. Nature 540, 418-422. doi:10.1038/nature20584

Ramsar Convention Secretariat (2016). The fourth strategic plan 2016-2024. Ramsar handbooks for wise use of wetlands, Gland, Switzerland: Ramsar Convention Secretariat, 5th Edn, Vol. 2.

Rebelo, L. M., Finlayson, C. M., and Nagabhatla, N. (2009). Remote sensing and GIS for wetland inventory, mapping and change analysis. J. Environ. Manage. 90, 2144-2153. doi:10.1016/j.jenvman.2007.06.027 
Saunders, D. L., Meeuwig, J. J., and Vincent, A. C. J. (2002). Freshwater protected areas: strategies for conservation. Conserv. Biol. 16, 30-41. doi:10.1046/j.15231739.2002.99562.x

Stirzaker, R., Biggs, H., Roux, D., and Cilliers, P. (2010). Requisite simplicities to help negotiate complex problems. Ambio 39, 600-607. doi:10.1007/s13280-010-0075-7

UNEP-WCMC and IUCN (2020). "Protected planet: the world database on protected areas (WDPA)," (Cambridge). Available at: https://www. protectedplanet.net/en/thematic-areas/wdpa, (Accessed August 9, 2020).

Venter, O., Sanderson, E. W., Magrach, A., Allan, J. R., Beher, J., Jones, K. R., et al. (2018). Last of the wild project, version 3 (LWP-3): 2009 human footprint, 2018 release. Palisades, NY: SEDAC.

Westgate, M. J., Likens, G. E., and Lindenmayer, D. B. (2013). Adaptive management of biological systems: a review. Biol. Conserv. 158, 128-139. doi:10.1016/j.biocon.2012.08.016
World Economic Forum (2019). The global risks report 2019. 14th Edn. Geneva, World Economic Forum.

Conflict of Interest: The authors declare that the research was conducted in the absence of any commercial or financial relationships that could be construed as a potential conflict of interest.

Copyright $\odot 2021$ Kingsford, Bino, Finlayson, Falster, Fitzsimons, Gawlik, Murray, Grillas, Gardner, Regan, Roux and Thomas. This is an open-access article distributed under the terms of the Creative Commons Attribution License (CC BY). The use, distribution or reproduction in other forums is permitted, provided the original author(s) and the copyright owner(s) are credited and that the original publication in this journal is cited, in accordance with accepted academic practice. No use, distribution or reproduction is permitted which does not comply with these terms. 